\title{
UPPER MANTLE STRUCTURE BENEATH THE CANADIAN SHIELD DERIVED FROM HIGHER MODES OF SURFACE WAVES
}

\author{
Masao NAKADA* and Michio HaShIZUME**,1) \\ * Ocean Research Institute, \\ the University of Tokyo, Tokyo, Japan \\ **College of Liberal Arts and Sciences, \\ Okayama University, Okayama, Japan
}

(Received October 28, 1983; Revised February 15, 1984)

\begin{abstract}
An analysis of surface waves including the fundamental and first higher modes, and $S a$ phase was made to determine the upper mantle structure beneath the Canadian Shield. Four earthquakes which occurred beneath the Canadian Shield were used for this purpose. By comparing synthetic and observed seismograms, the shear velocity structure of the upper mantle was determined. The shear velocity structure of the shallower part was determined mainly using the fundamental and first higher modes. The structure in the deeper part was mainly constrained by the $S a$ phase. Phase of Love type $S a$ wave was successfully reproduced by a uniform shear velocity structure over the entire area of the Canadian Shield. The average shear velocity of the upper mantle above the depth of $400 \mathrm{~km}$ obtained in this study is $4.67 \mathrm{~km} / \mathrm{sec}$, which is higher than velocities of any other models presented before. The low velocity layer of the upper mantle is poorly developed. Since the polarization anomaly of surface waves was not observed for the fundamental and first higher modes and $S a$ phase, anisotropic velocity structure does not exist in the upper mantle beneath the Canadian Shield.
\end{abstract}

\section{Introduction}

The velocity structure beneath the Canadian Shield was first determined by BRUNE and DORMAN (1963). They determined the upper mantle structure mainly using surface waves of the fundamental mode. The earth model, named CANSD, has upper mantle velocities higher than those of any other models. IBRAHIM and Nuttli (1967), Kovach and Robinson (1969), ANDERSON and Julian (1969), HeLMBERGER and ENGEN (1974), and Romanowicz (1979) have reported several different upper mantle structures beneath the north American continent. Their studies suggested the existence of lateral heterogeneity of the upper mantle within the single continental area, which might reflect different evolutional stages of the Canadian Shield (PoupINET, 1977, 1979; BuCHBInder and PoupINET, 1977; WICKENS and BUCHBINDER, 1980).

1) Now at Earth Science Division, Science Sector, UNESCO, 7, place de Fontenoy, 75,700 Paris, France. 
Another topic in the study of earth structure is the anisotropy of the upper mantle (MCEvilly, 1964; Forsyth, 1975; Mrtchell and HerrmanN, 1979; DzIewonski and ANDERSON, 1981; KirKwood and CrAMPIN, 1981a, b). Based on the fundamental mode Love and Rayleigh waves in the central United States, McEviLly (1964) concluded that SV velocities of the upper mantle and lower crust are $8 \%$ lower than SH velocities. FORSYTH (1975) obtained similar results for the oceanic upper mantle. DzIEwONSKI and ANDERSON (1981) pointed out that the low velocity layer is not required in the upper mantle, if anisotropy is assumed.

Recently, several attempts to make use of higher mode surface waves have been made in the study of the upper mantle structure (CARA, 1978, 1979; PrIESTLY et al., 1980). Surface waves, by their nature, provide some gross information about the earth structure. Higher mode surface waves are particularly sensitive to the structural variation of the upper mantle (KovaCH and ANDERSON, 1964).

In this study, the upper mantle structure beneath the Canadian Shield was investigated mainly using the higher mode surface waves. Four intraplate earthquakes were used for this purpose. On the seismograms corresponding to these events, the conventionally called $S a$ phase was observed clearly over a wide area. As for the nature of the $S a$ phase, several studies have already been made and the phase is believed to be a kind of higher mode surface waves whose energy is trapped mainly in the upper mantle (CALOI, 1953, 1954; BRUNE, 1965; CALCAGNILE and PANZA, 1974; NAKANISHI et al., 1976; KAUSEL et al., 1977). By using these higher mode surface waves, we determined the upper mantle structure beneath the Canadian Shield.

\section{Data and Analysis}

\subsection{Data}

Four earthquakes which occurred under the Canadian Shield were used in this study. Their location and source parameters are listed in Table 1. The source parameters were determined by HASHIZume (1973, 1974, 1977) mainly using fundamental mode surface waves. Seismograms were collected from the Canadian Seismic Network stations (CSNW). The stations used in this study are shown in Fig. 1 together with the epicenters of the earthquakes. A few examples of observed seismograms are reproduced in Fig. 2. Seismograms are arranged at reduced travel times of velocity $4.5 \mathrm{~km} / \mathrm{sec}$ (arrow). T, R, and V indicate transverse, radial, and vertical components, respectively. The lower trace of each component is synthetic seismogram reproduced by the earth model, CANSD-r, proposed in the present paper for the Canadian Shield. Deconvolution of instrumental response was made digitally, and a Butterworth filter (GoLD and RADER, 1969) with a pass-band between 5 and $50 \mathrm{sec}$ has been applied.

The seismograms include five types of signals: 


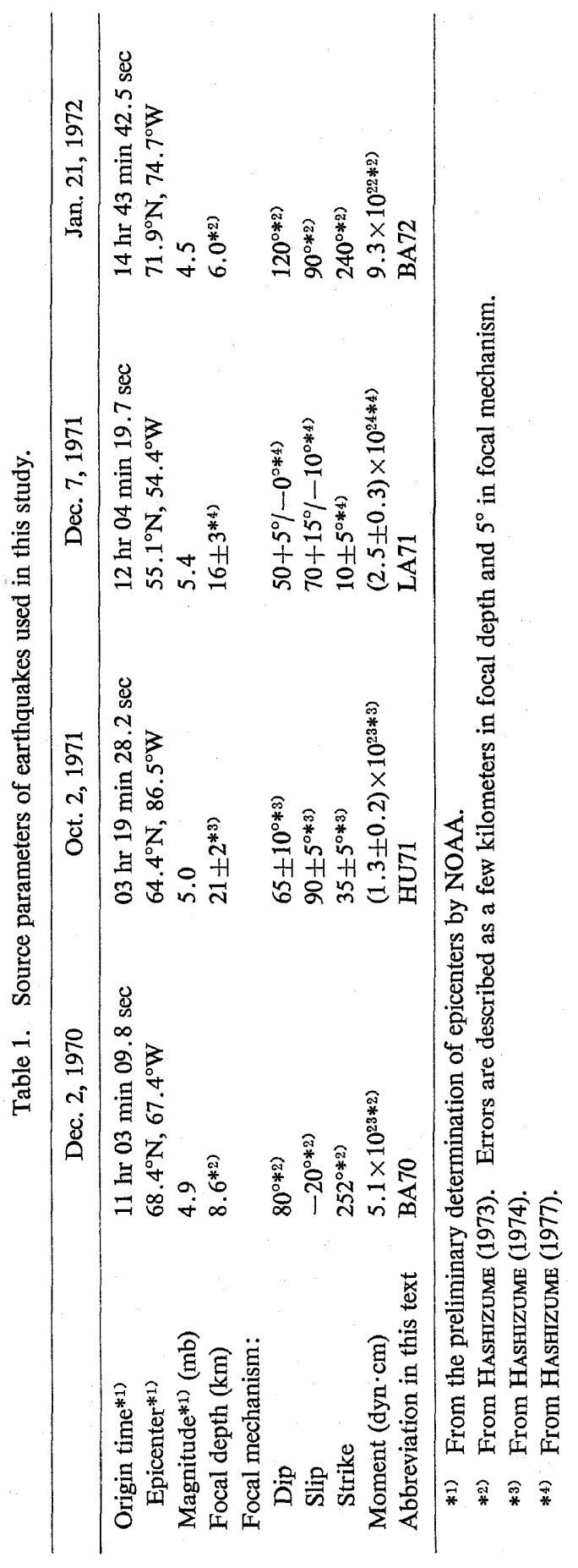




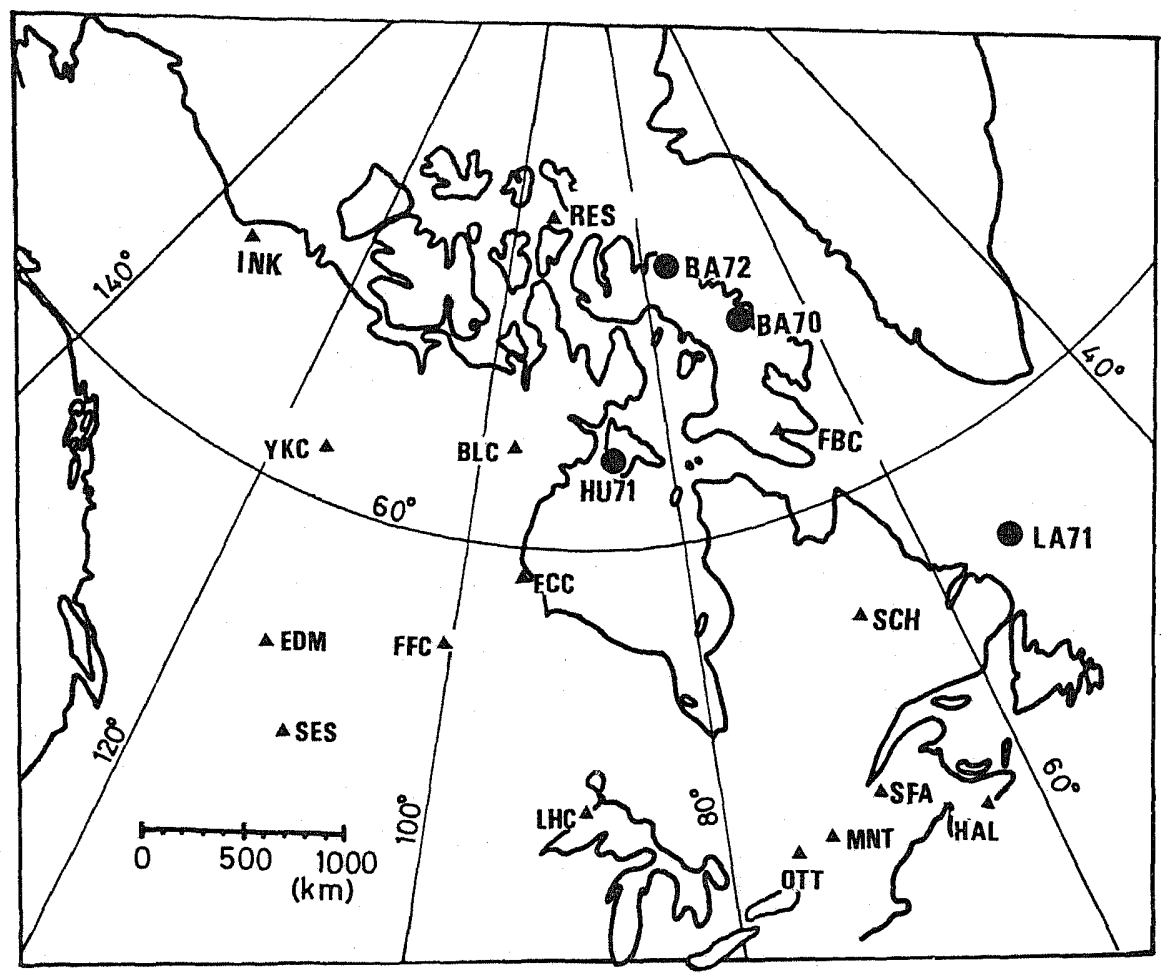

Fig. 1. Locations of the four earthquakes (BA70, HU71, LA71, and BA72) and seismic stations used in this study.

1. Fundamental mode Love waves in a velocity range between $3.3 \mathrm{~km} / \mathrm{sec}$ and $3.7 \mathrm{~km} / \mathrm{sec}$.

2. Fundamental mode Rayleigh waves in a velocity range between $3.0 \mathrm{~km} / \mathrm{sec}$ and $3.3 \mathrm{~km} / \mathrm{sec}$. Note that separation of fundamental mode Love and Rayleigh waves is almost perfect and the phase shift of vertical and radial components is almost exactly $\pi / 2$ as theory predicts.

3. Waves in a velocity range between $3.7 \mathrm{~km} / \mathrm{sec}$ and $4.3 \mathrm{~km} / \mathrm{sec}$. The wave trains consist mainly of the first higher mode.

4. A pulse-like signal with a group velocity about $4.5 \mathrm{~km} / \mathrm{sec}$. The signal has been called as $S a$ phase (CALOI, 1953, 1954; BRUNE, 1965). This phase is observed on a seismogram of the transverse component. In the following discussion, we shall call this phase Love type $S a$ phase.

5. A pulse-like signal with a group velocity range between $4.6 \mathrm{~km} / \mathrm{sec}$ and $4.8 \mathrm{~km} / \mathrm{sec}$. This phase is observed on seismograms on the vertical and radial components. In the following discussion, we shall call this phase Rayleigh type $S a$ phase.

Hashizume (1973, 1974, 1976, 1977) studied the crustal structure beneath 


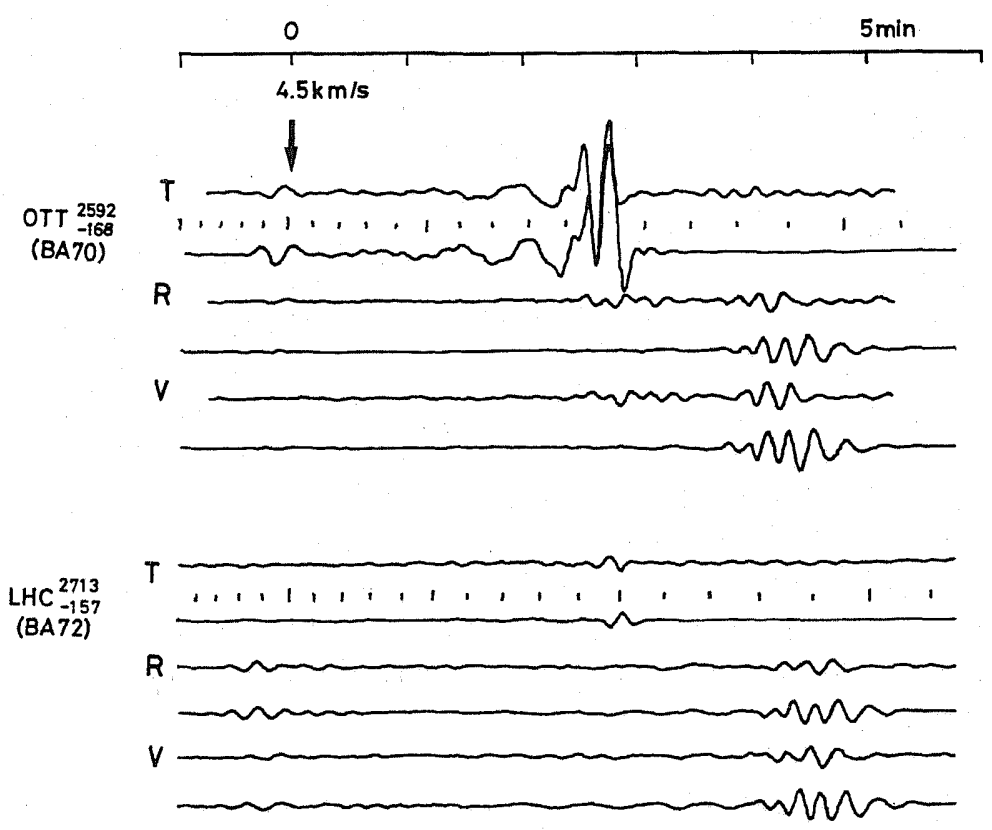

Fig. 2. Examples of observed and synthetic seismograms arranged at a reduced traveltime velocity $4.5 \mathrm{~km} / \mathrm{sec}$ (arrow). The first, third, and fifth traces for each station are transverse $(T)$, radial $(R)$, and vertical (V) components of the observed seismograms, respectively. The second, fourth, and sixth traces are synthetic seismograms of the components in the same order as above. Synthetic seismograms were reproduced by CANSD-r. Group velocities are indicated at every $0.1 \mathrm{~km} / \mathrm{sec}$ with tick marks and at every $0.5 \mathrm{~km} / \mathrm{sec}$ with thick tick marks. Numbers to the right of the station code and the epicentral distance $(\mathrm{km})$ and azimuthal direction $\left(^{\circ}\right)$ from epicenter to station. The azimuthal direction is measured clockwise from the north.

the Canadian Shield using the fundamental mode Love and Rayleigh waves. In the present study, we paid special attention to the higher modes recorded on the seismograms.

\subsection{Analysis}

The epicentral distance to the stations is not always large enough for the higher modes to be completely resolved into each mode on the seismograms. Therefore, we tried to reproduce the waves by normal mode superposition as was adopted by KAWASAKI (1978). First eigenvalues, internal stress, and strain filed were calculated to the fourteenth higher mode using the computational algorithm developed by HASKELL (1953) and DUNKIN (1965). As a result of the numerical experiments, it was found that the internal displacement in a depth range shallower than $700 \mathrm{~km}$ could be evaluated without numerical instability by this algorithm. 
The calculation was made using an earth flattening approximation (ANDERSON and ToKsöz, 1963; Biswas and KNOPOFF, 1970; BISWAS, 1972). For Love waves, an exact analytical solution exists. For Rayleigh waves, however, only an approximate solution is available. According to numerical studies by KovACH and ANDERSON (1964), the difference in the eigenvalues between a spherical earth model and a flat earth approximation model is negligible for periods less than $25 \mathrm{sec}$ in both fundamental and higher modes. Since a period range of the higher modes used in this study is less than $25 \mathrm{sec}$, the earth flattening approximation could be taken to be of sufficient accuracy.

Synthetic seismograms were reproduced using the source parameters determined by Hashizume (1973, 1974, 1977), based on SaITo's formulation (1967). The apparent $Q$-value is set at 1,000 for the entire depth range throughout this calculation. In this paper, we determine the shear velocity structure of the upper mantle mainly reproducing the pulse-like $S a$ phase with a group velocity about $4.5 \mathrm{~km} / \mathrm{sec}$, and we do not discuss the $Q$-value of the upper mantle. The best fitting earth model was determined from comparison of synthetic and observed seismograms.

\subsection{Effects of slight changes in crustal structure and source parameters}

The effect of errors in source parameter determination on the excitation of higher mode surface waves was evaluated by changing the parameters. It was found that the estimated uncertainty in the source parameters (HASHIZUME, 1973, 1974,1977 ) had only a minor influence on the synthetic seismograms. The effects on synthetic seismograms of slight changes of focal depth and slip angle are illus. trated in Fig. 3. The effect of a regional variation of crustal structure on normal mode excitation was also found not to be important.

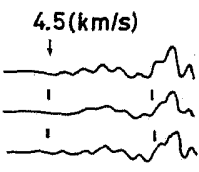

$B L C(T)$

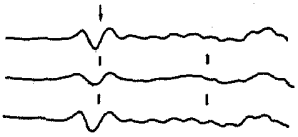

$\operatorname{MNT}(T)$

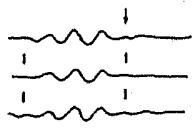

$\operatorname{EDM}(R)$

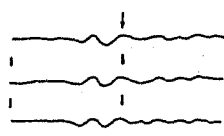

LHC(V)

Fig. 3. Effects of changes in source parameters on the excitation of higher mode surface waves. The upper trace for each station is synthetic seismograms based on CANSD$r$ calculated using the same source parameters of BA70 (Table 1). The middle and lower traces are synthetic seismograms calculated by changing the focal depth to $15 \mathrm{~km}$ and slip angle to $0^{\circ}$, respectively. The other source parameter is set at the same values as given in Table 1 . Times are indicated at every minute with thick tick marks. T, R, and V denote the transverse, radial, and vertical components, respectively. Note that the effect due to a change of source parameter is negligible. 


\section{Upper Mantle Structure beneath the Canadian Shield}

Earth structure beneath the Canadian Shield was determined by the abovementioned analysis of the fundamental and first higher mode surface waves, and the Love and Rayleigh type $S a$ phases. Wave energy of the fundamental mode Love and Rayleigh waves at the period less than $20 \mathrm{sec}$ is almost confined in the crust. A slight difference between the observed and synthetic seismograms at this period range could be attributed to a slight lateral variation of the crustal structure in the Canadian Shield (HashIzUME, 1976).

Considerable numbers of models were examined by trial and error to search for the best fitting model. Several models among them are illustrated in Fig. 4. The earth structure of CANSD- $r$ we propose is listed in Table 2, and the shear

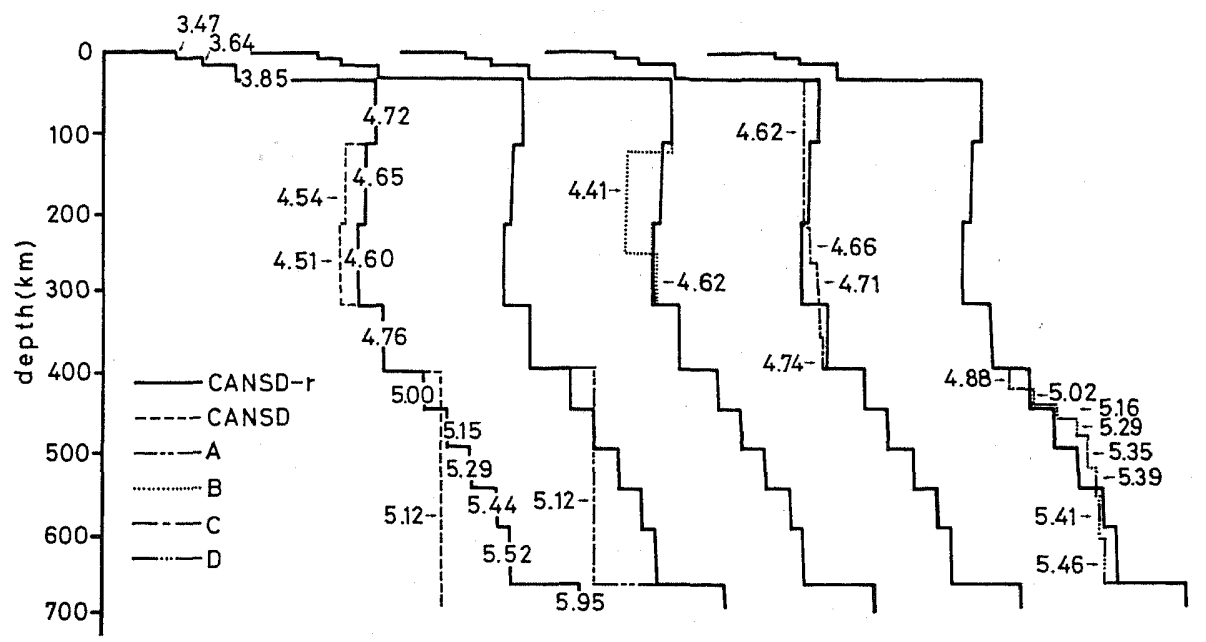

Fig. 4. Shear velocity structures discussed in this study.

Table 2. Earth structure of CANSD-r.

\begin{tabular}{cccc}
\hline Depth $(\mathrm{km})$ & $V_{\mathrm{P}}(\mathrm{km} / \mathrm{sec})$ & $V_{\mathrm{S}}(\mathrm{km} / \mathrm{sec})$ & $D\left(\mathrm{~g} / \mathrm{cm}^{3}\right)$ \\
\hline $0.0-6.0$ & 5.64 & 3.47 & 2.70 \\
$6.0-16.5$ & 6.15 & 3.64 & 2.80 \\
$16.5-35.2$ & 6.60 & 3.85 & 2.85 \\
$35.2-115.2$ & 8.10 & 4.72 & 3.30 \\
$115.2-215.2$ & 8.20 & 4.65 & 3.40 \\
$215.2-315.2$ & 8.30 & 4.60 & 3.45 \\
$315.2-395.2$ & 8.70 & 4.76 & 3.50 \\
$395.2-445.2$ & 9.01 & 5.00 & 3.59 \\
$445.2-495.2$ & 9.32 & 5.15 & 3.69 \\
$495.2-545.2$ & 9.62 & 5.29 & 3.79 \\
$545.2-595.2$ & 9.90 & 5.44 & 3.89 \\
$595.2-665.2$ & 10.15 & 5.52 & 3.96 \\
$665.2-$ & 10.75 & 5.95 & 4.38 \\
\hline
\end{tabular}



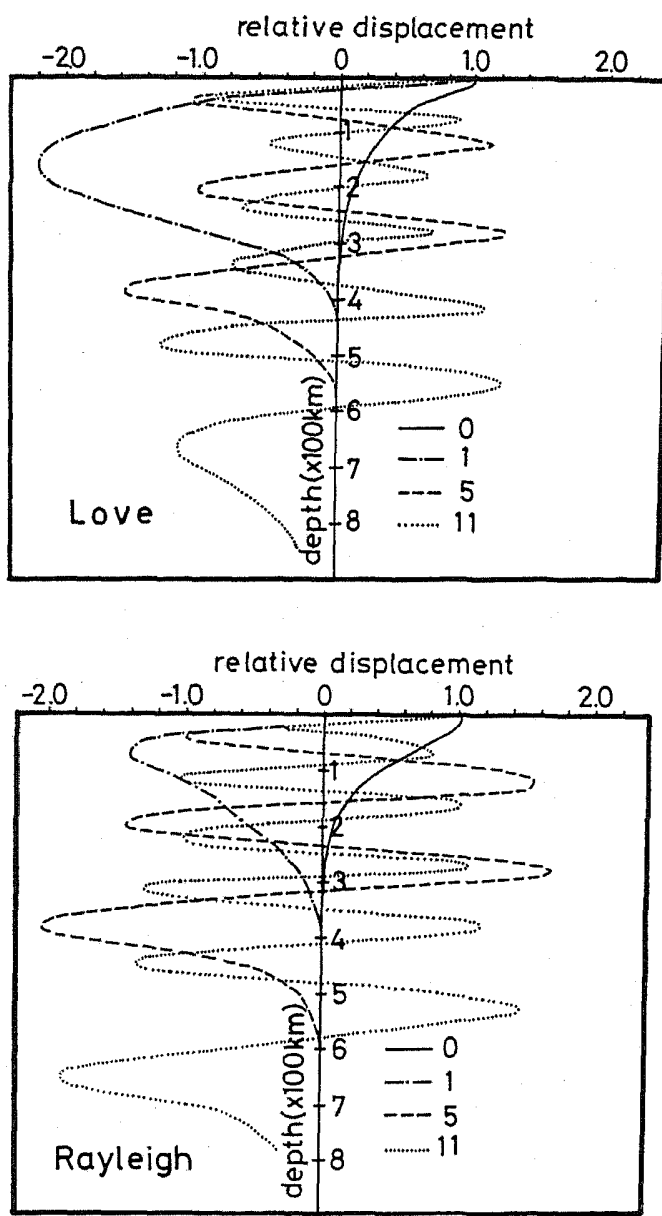

Fig. 5. Distributions of normalized horizontal displacement for the fundamental mode at the period of $40 \mathrm{sec}$ and the first, fifth, and eleventh higher modes at the period of $15 \mathrm{sec}$. The model is CANSD-r.

velocity structure is also shown in Fig. 4. The depth distribution of the normalized displacement corresponding to CANSD-r is shown for the fundamental mode at the period of $40 \mathrm{sec}$ and higher modes at the period of $15 \mathrm{sec}$ in Fig. 5. The wave energy of the fundamental mode at the period of $40 \mathrm{sec}$ penetrates about $150 \mathrm{~km}$ into the earth's deep interior. Wave energy of the first, fifth, and eleventh higher modes at the period of $15 \mathrm{sec}$ penetrate about 250,400 , and $670 \mathrm{~km}$, respectively.

Our numerical experiments determined that a part of the observed seismograms in a group velocity ranging between $3.7 \mathrm{~km} / \mathrm{sec}$ and $4.3 \mathrm{~km} / \mathrm{sec}$ is mainly composed of the first higher mode. The Love type $S a$ phase can be reproduced by summing up the first five higher modes. The Rayleigh type $S a$ phase can be 


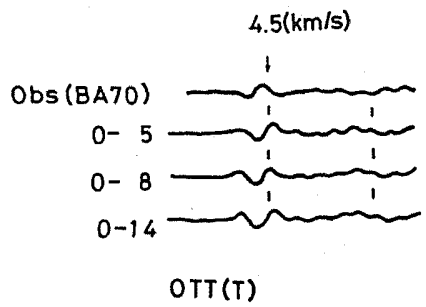

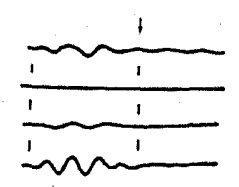

SES(R)

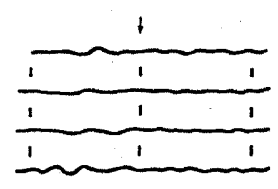

$\operatorname{SES}(V)$

Fig. 6. Each trace in the figure was reproduced by adding higher modes over the range shown in the figure. Arrows indicate a group velocity $4.5 \mathrm{~km} / \mathrm{sec}$. The model is CANSD-r. $\mathrm{T}, \mathrm{V}$, and $\mathrm{R}$ denote transverse, vertical, and radial components, respectively. Times are indicated at every minute with thick tick marks.

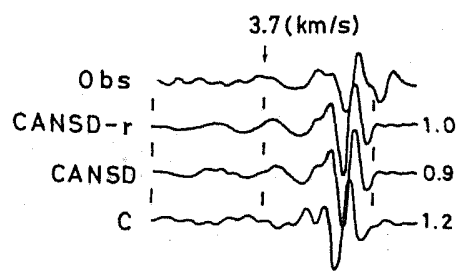

$\operatorname{EDM}(B A 70)$

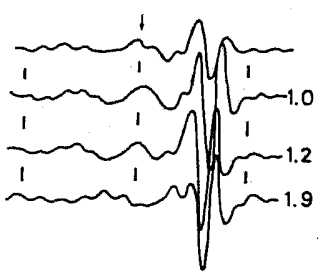

LHC(BA70)

Fig. 7. Fundamental mode Love waves at the period of about 40 sec. Each trace represents observed and synthetic seismograms for the model indicated. Times are shown at every minute with thick tick marks. The value to the right of each synthetic seismogram is the normalized root-meansquare deviation (rms) between observed and synthetic seismograms. Each rms is normalized by the value between observed seismogram and synthetic one by CANSD-r.

reproduced by summing the higher modes up to the fourteenth. A few examples of the numerical experiments are given in Fig. 6. P-wave velocities and densities do not affect results greatly, as was shown by KovACH and ANDERSON (1964) and Brune (1965). Therefore, we shall not discuss the P-wave velocity and the density structure hereafter.

The fundamental mode Love waves at a group velocity of about $3.7 \mathrm{~km} / \mathrm{sec}$ and period of about $40 \mathrm{sec}$ are clearly observed on the seismograms at, for example, EDM, SES, and LHC of BA70. The wave energy penetrates about $150 \mathrm{~km}$. A few examples of synthetic seismograms reproduced by CANSD, CANSD-r, and model $\mathrm{C}$ are shown in Fig. 7. Shear wave velocity of CANSD and CANSD-r in a depth range between $40 \mathrm{~km}$ and $120 \mathrm{~km}$ is $4.72 \mathrm{~km} / \mathrm{sec}$. The shear wave velocity of model $\mathrm{C}$ in this depth range is $4.64 \mathrm{~km} / \mathrm{sec}$. Observed seismograms are better reproduced by the synthetic seismograms based on CANSD or CANSD- $r$ than that on model $\mathrm{C}$.

Small amplitude wave trains in a group velocity range between $3.7 \mathrm{~km} / \mathrm{sec}$ 
and $4.3 \mathrm{~km} / \mathrm{sec}$ are recorded on most of the observed seismograms. These wave trains can be reproduced mainly by surface waves of the first higher mode. The wave energy of the first higher mode penetrates about $250 \mathrm{~km}$. Note that one to one correspondence of peak and trough between observed and synthetic seismograms can be seen for both the Love and Rayleigh waves (Fig. 2).

The Love type $S a$ phase can be found on seismograms observed at stations with epicentral distances more than $2,200 \mathrm{~km}$. This phase is pulse-like and has a group velocity of about $4.5 \mathrm{~km} / \mathrm{sec}$. This phase can be reproduced by summing the higher modes up to the fifth (Fig. 6). The wave energy penetrates about 400 $\mathrm{km}$. A few examples of observed and synthetic Love type $S a$ phase reproduced by models CANSD, CANSD-r, B, and C are shown in Fig. 8. Synthetic seismograms for CANSD give a pulse-like $S a$ phase, but its group velocity is about 0.1 $\mathrm{km} / \mathrm{sec}$ lower than the observed one. The average shear wave velocity above $400 \mathrm{~km}$ depth of model C and the CANSD-r is the same. Synthetic seismograms for model $\mathrm{C}$ give a pulse-like $S a$ phase and its group velocity is about $4.5 \mathrm{~km} / \mathrm{sec}$. However, considering the fit between observed and synthetic fundamental mode Love waves at a group velocity of about $3.7 \mathrm{~km} / \mathrm{sec}$ and period of about $40 \mathrm{sec}$, the shear wave velocity structure above $400 \mathrm{~km}$ depth of CANSD-r may be accepted.

The $S a$ phase reproduced by model B is not pulse-like. The fit between observed and synthetic seismograms for the first higher mode based on model B is also poor, although it is not shown here. Such a well developed low velocity layer as is represented by model B is excluded from the possible earth models for the Canadian Shield. A synthetic Love type $S a$ phase by CANSD-r can reproduce the observed one in respect to both the shape and group velocity. The shear velocity in a depth range between $100 \mathrm{~km}$ and $300 \mathrm{~km}$ is 2 or $3 \%(0.1 \mathrm{~km} / \mathrm{sec})$ higher than that of CANSD.

The Rayleigh type $S a$ phase can be found on seismograms at EDM, LHC, and SES of BA70 and EDM and LHC of BA72. A few examples of synthetic

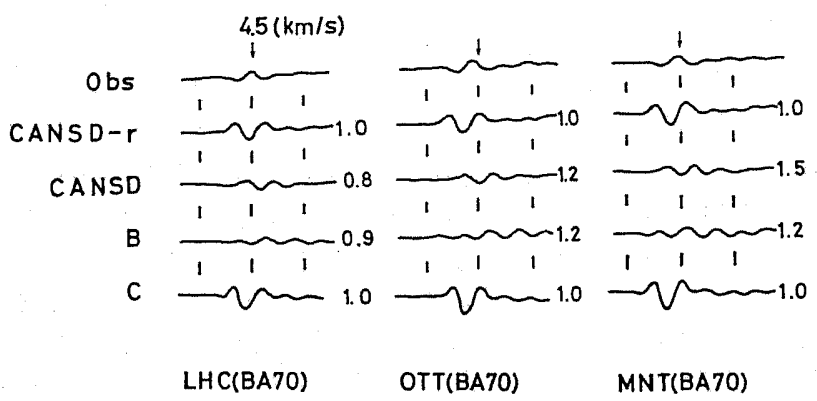

Fig. 8. Observed and synthetic Love type $S a$ phase reproduced using the model indicated. Times are shown at every minute with thick tick marks. The normalized rms is shown to the right of each synthetic seismogram. 


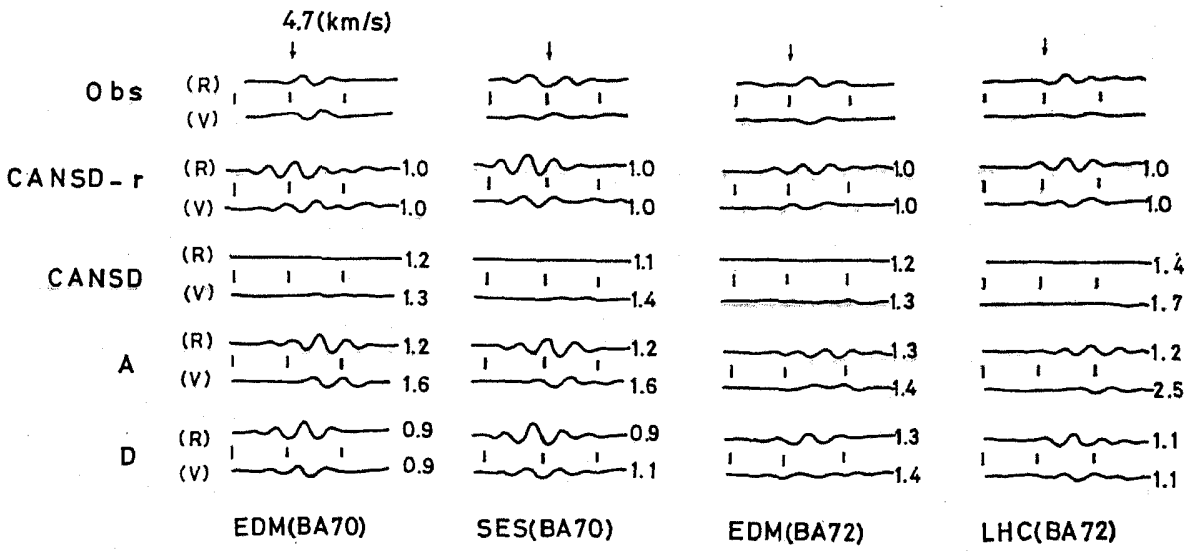

Fig. 9. Observed and synthetic Rayleigh type $S a$ phase reproduced using the model indicated. The upper trace of each pair is the radial component and lower trace the vertical component. Times are shown at every $0.5 \mathrm{~min}$ with thick tick marks. The normalized rms is shown to the right of each synthetic seismogram.

Rayleigh type $S a$ phases reproduced by models CANSD, CANSD-r, A, and D are shown in Fig. 9. Reproduction of this phase requires surface waves to be summed up to the fourteenth higher mode (Fig. 6). The wave energy penetrates more than $670 \mathrm{~km}$ into the earth's deep interior. This phase cannot be excited by a structure like CANSD shown in Fig. 4 . Since the fit between observed and synthetic Rayleigh type $S a$ phase is not so good, the shear velocity structure in a depth range between $400 \mathrm{~km}$ and $670 \mathrm{~km}$ is not determined by only this phase. But a shear velocity jump at the depth near $670 \mathrm{~km}$ may be essential to produce this phase. The shear velocity structure of CANSD-r in that depth range is put to be almost the same with that of PREM (DZIEwONSKI and ANDERSON, 1981).

Phase difference of up to half a wavelength can be seen between observed and synthetic $S a$ phases at some locations. A shift of one wavelength between observed and synthetic seismograms at an epicentral distance of $2,500 \mathrm{~km}$ corresponds to $2.5 \%$ difference of group velocity. We cannot find such a large shift on a seismogram for any stations, and the shift is at most half a wavelength. Therefore, the shear wave velocity structure of the upper mantle beneath the Canadian Shield may be laterally uniform in an order of $1 \%$ of group velocity. The seismograms from LA71 also show the Love type Sa phases (Fig. 10). The group velocity is about $4.5 \mathrm{~km} / \mathrm{sec}$. The epicenter of LA71 is located on the continental margin. Misfit of amplitude may be attributed to difficulty in the evaluation of surface wave excitation due to the lateral heterogeneity.

Finally, we wish to discuss the nature of the $S a$ phase. The $S a$ phase can be found on the seismograms recorded at stations with epicentral distances greater $2,200 \mathrm{~km}$ in our case. Figure 11 shows reduced travel-times of $\mathrm{S}$ waves refracted and/or reflected once at depths indicated in the figure. Two cases corresponding 

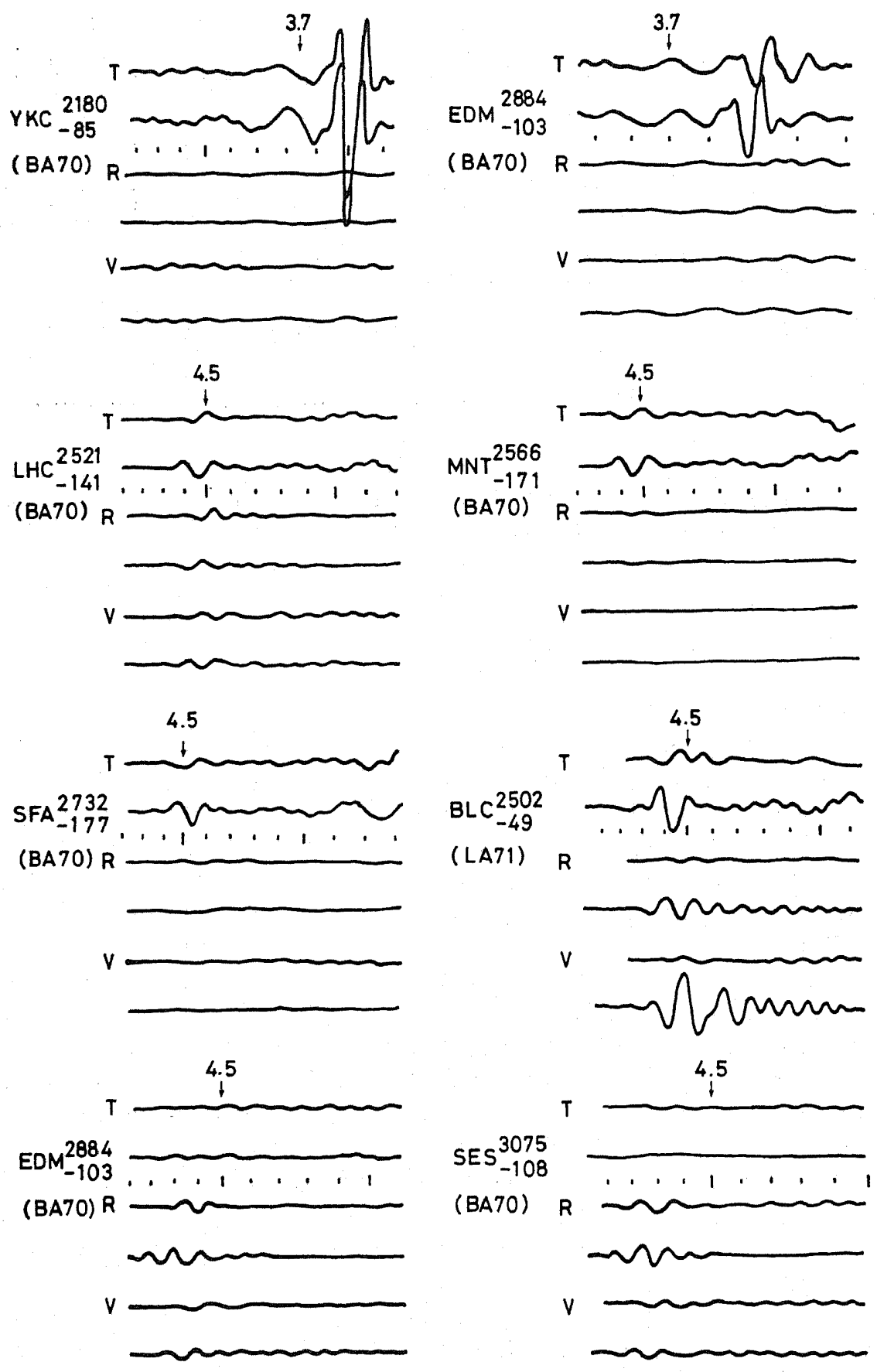

Fig. 10 
to CANSD- $r$ and model $\mathrm{C}$ are given. The travel-times based on these models are roughly identical to those of the $S a$ phase. From the standpoint of ray theory, the $S a$ phase is considered to be a phase made by superposition of refraction and/or refiection from the entire upper mantle. This interpretation may be justified by the fact that Love waves can be reproduced almost perfectly only by waves totally reflected once at a boundary (KAWASAKI, 1978). Dispersion curves of group velocity for Love and Rayleigh waves for CANSD- $r$ are shown in Fig. 12. The Love type $S a$ phase may correspond to minima in the group velocity curves at about $4.5 \mathrm{~km} / \mathrm{sec}$ for the fourth and fifth modes. The Rayleigh type $S a$ phase may correspond to minima in the group velocity curves of about $4.8 \mathrm{~km} / \mathrm{sec}$ of more than ninth mode.

NAKANISHI et al. (1976) showed that the Sa phase can be observed at stations located at epicentral distances greater than $5,000 \mathrm{~km}$. CALCAGNILE and PANZA (1974) showed that the $S a$ phase is excited by earthquakes with focal depths greater than $50 \mathrm{~km}$. According to our numerical experiments, the observed Love and Rayleigh type $S a$ phases could be systematically reproduced by the shear velocity structure of CANSD-r. Namely the condition of excitation of $S a$ phase may depend strongly on the regional earth structure.

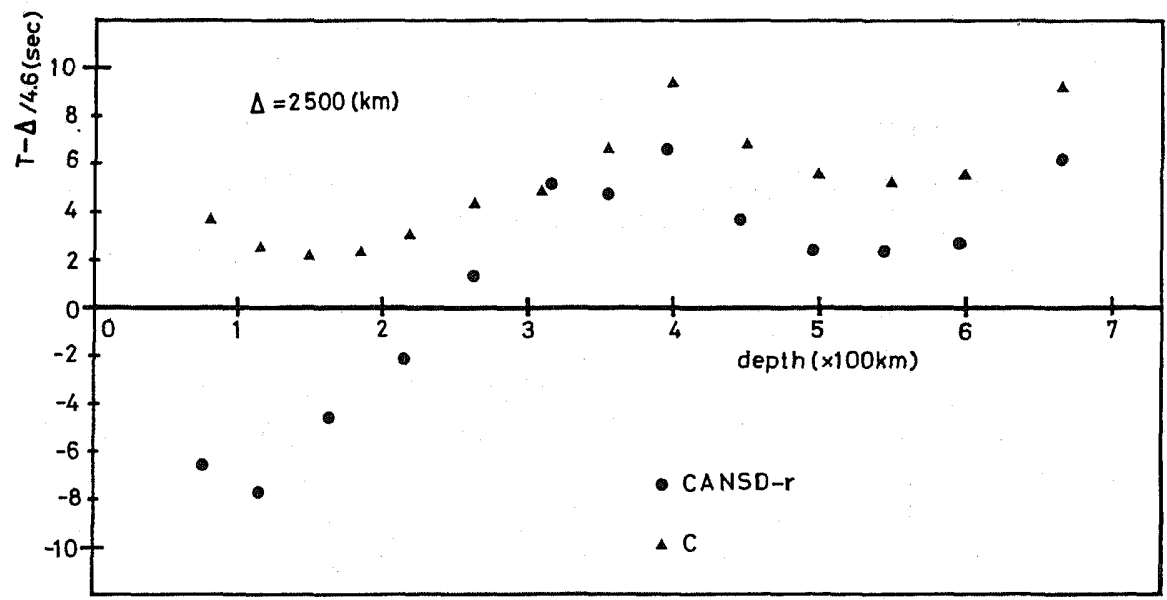

Fig. 11. Reduced travel-times of $\mathrm{S}$ waves refracted and/or reflected at depths indicated in the figure. The velocity models are CANSD- $r$ and C.

Fig. 10. Examples of observed and synthetic seismograms. The first, third, and fifth traces for each station are transverse (T), radial (R), and vertical $(V)$ components of the observed seismograms, respectively. The second, fourth, and sixth traces are synthetic seismograms of the components in the same order as above. Synthetic seismograms were reproduced by CANSD-r. Group velocities are indicated at every $0.1 \mathrm{~km} / \mathrm{sec}$ with tick marks and every $0.5 \mathrm{~km} / \mathrm{sec}$ with thick tick marks. Numbers to the right of the station code are the epicentral distance $(\mathrm{km})$ and azimuthal direction $\left(^{\circ}\right)$ from epicenter to station. 

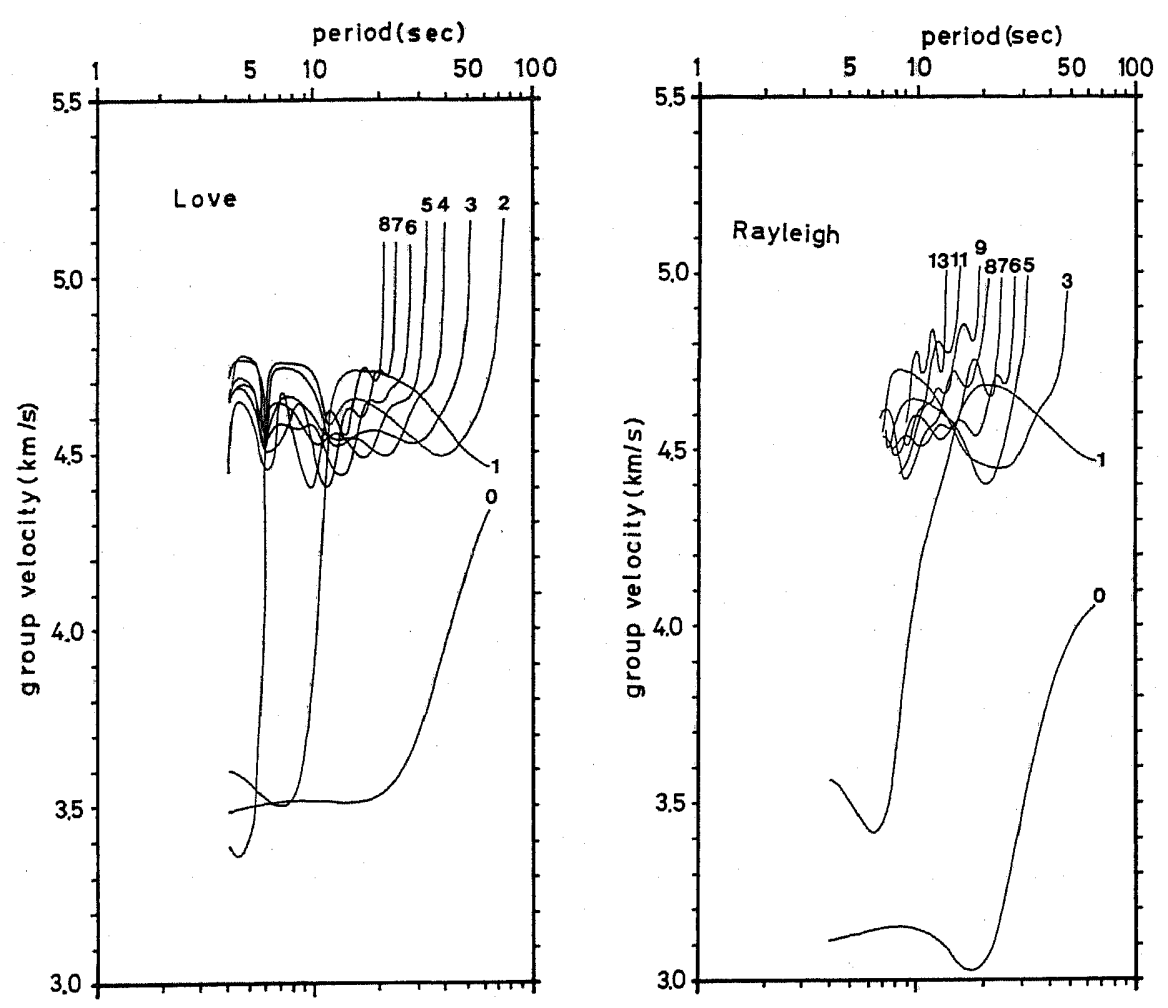

Fig. 12. Dispersion curves of group velocity for the Love and Rayleigh waves. The model is CANSD-r. The numbers shown denote mode number.

\section{Anisotropy of Seismic Wave Velocity beneath the Canadian Shield}

A number of studies have found evidence of anisotropy in the upper mantle (McEvilly, 1964; Forsyth, 1975; Crampin and KIng, 1977; MrtChell and Herrmann, 1979; Kirkwood and CRampin, 1981a, b; Dziewonski and ANDERSON, 1981). MCEvilly (1964) and MitChell and HerRmanN (1979) report that SH-wave velocities of the upper mantle beneath the central part of the United States are several percent higher than SV-wave velocities. The conclusion was reached because the dispersion of the fundamental mode Love and Rayleigh waves could not be explained by a single model. In the present study, however, the Love and Rayleigh waves can be explained by a single model.

KIRKWOOD and CRAmpin (1981a) showed that polarization anomalies were caused by local anisotropic structure within a few wavelengths of the recording station. They suggested that this fact can be utilized as a good diagnostic of anisotropy rather than that of the velocity dispersion averaged over long paths. Examples of polarization diagrams of observed fundamental mode Love and Rayleigh waves are given for periods less than $25 \mathrm{sec}$ in Fig. 13. Stations given 

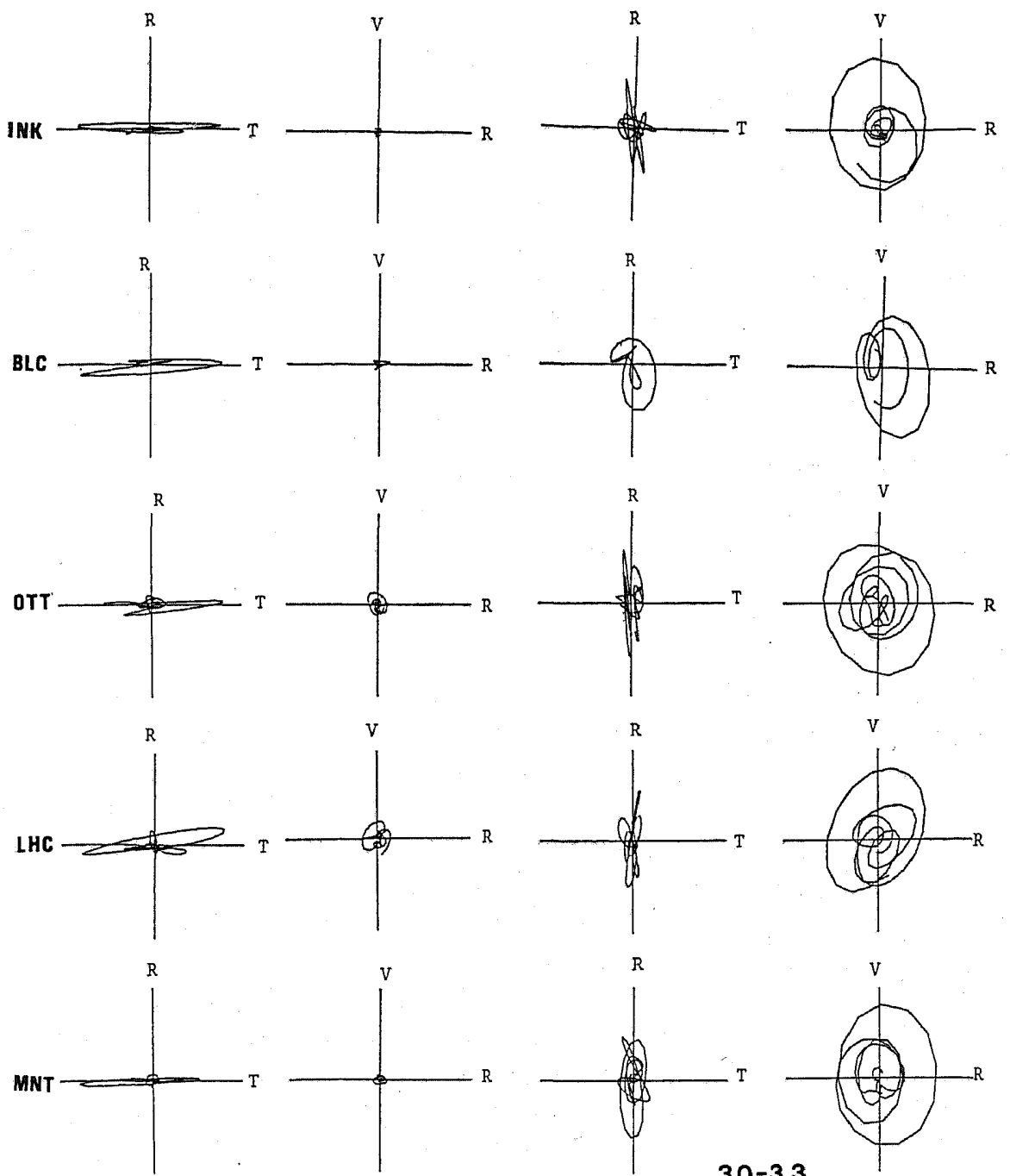

3.3-3.7

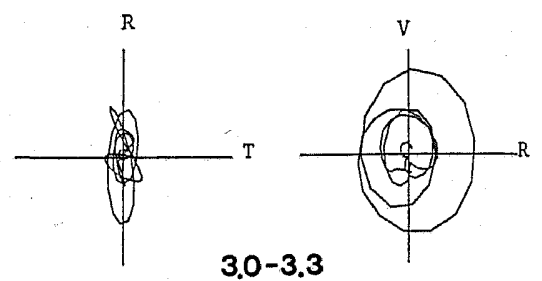

Fig. 13. Polarization diagrams of fundamental mode surface waves for the range of apparent velocities shown in the lower part. $T, R$, and $V$ represent transverse, radial, and vertical directions, respectively.

in the figure are selected so as to cover a wide range of azimuthal directions. Particle motion of fundamental mode Love waves for group velocities between $3.3 \mathrm{~km} / \mathrm{sec}$ and $3.7 \mathrm{~km} / \mathrm{sec}$ is observed only on a transverse component. On the other hand, particle motion of the fundamental mode Rayleigh waves for group velocities between $3.0 \mathrm{~km} / \mathrm{sec}$ and $3.3 \mathrm{~km} / \mathrm{sec}$ is limited to the sagital plane. The result suggests that horizontal and vertical anisotropy does not exist above and below the Moho discontinuity beneath the Canadian Shield. Wave energy 
of fundamental mode Love waves at the period of $40 \mathrm{sec}$ penetrates about $150 \mathrm{~km}$ (Fig. 5). Seismograms recorded at EDM, LHC, and OTT for BA70, for example, show that surface waves of the fundamental mode Love waves at a group velocity of about $3.7 \mathrm{~km} / \mathrm{sec}$ and the period of about $40 \mathrm{sec}$ do not show any sign of polarization (Fig. 10), i.e., these synthetic and observed waves appear only on a transverse component.

Wave energy of Love and Rayleigh type $S a$ phases at the period of $15 \mathrm{sec}$ penetrates about $400 \mathrm{~km}$ and $670 \mathrm{~km}$, respectively (Fig. 5). The Love type $S a$ phase observed at OTT, MNT, and SFA for BA70, for example, appears only on seismograms of the transverse component as the theoretical seismograms predict (Fig. 2 and Fig. 10). The Rayleigh type $S a$ phase, on the other hand, at SES and EDM for BA70 and LHC and EDM for BA72, appears only on seismograms of radial and vertical components, and not on the transverse component (Fig. 2 and Fig. 10). Anisotropy of the seismic wave velocity could not be detected in the present analysis for the crust and the upper mantle beneath the Canadian Shield.

\section{Concluding Remarks}

Four earth models CANSD (BRUNE and DORMAN, 1963), SHR-14(HELMBERGER and ENGEN, 1974), PREM (DZIEwonski and ANDERSON, 1981), and CANSD-r are reproduced in Fig. 14. The shear wave velocity structure in a depth range between $200 \mathrm{~km}$ and $400 \mathrm{~km}$ is not so different in these models; however, the shear wave velocities of the upper mantle above $200 \mathrm{~km}$ depth of the CANSD- $r$ are distinctively higher than those of other models. Therefore, the shear wave velocities of the upper mantle above $200 \mathrm{~km}$ depth beneath the Canadian Shield may be higher than those of other regions. PoupINET (1977) studied the shear wave velocity difference in the Canadian Shield and surrounding areas. His results showed that shear-wave velocities of the upper mantle beneath the Canadian Shield are laterally uniform and higher than those of surrounding areas. So the shearwave velocity structure of the upper mantle above the depth of about $200 \mathrm{~km}$ may vary across the North American Continent.

HASHIZUME (1976) discussed the lateral uniformity of the crust beneath the Canadian Shield by analysing the initial phase of the fundamental mode surface waves. According to his results, regional variation of shear wave velocities in the crust is less than $0.5 \%$ beneath the Canadian Shield. A uniform model for the upper mantle structure of this area has also been derived by the present analysis. This lateral uniformity of the upper mantle including the crust beneath the Canadian Shield will be useful for elucidating the formation of continent and mantle dynamics (JORDAN, 1975a, b).

DZIEWONSKI and ANDERSON (1981) found that the low velocity layer in the upper mantle can be replaced partly by vertical anisotropy. CRAMPIN and KING (1977) showed that anisotropy exists in the upper mantle beneath Eurasia. KIRKWOOD and CRAMPIN (1981b) showed anisotropy exists in the oceanic upper mantle 


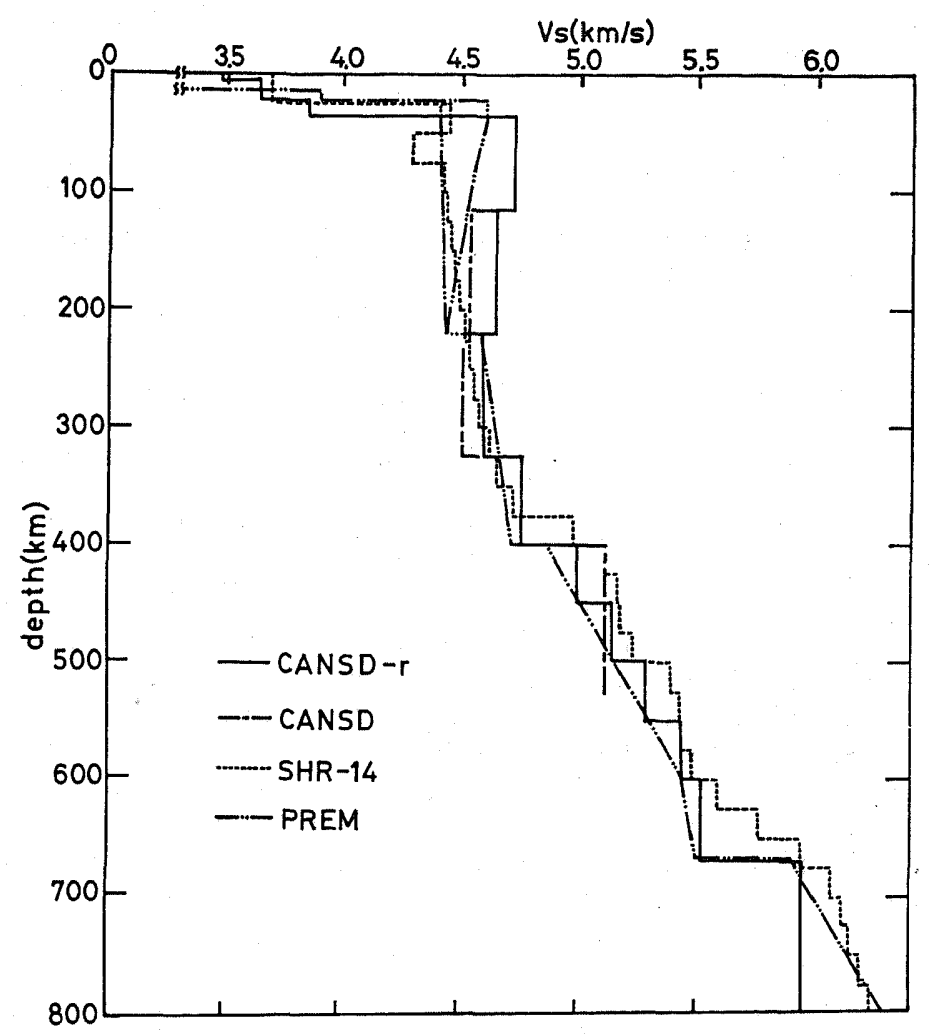

Fig. 14. Shear velocity structure of CANSD-r proposed for the upper mantle structure beneath the Canadian Shield and those of some other models. Anisotropy in PREM is shown by highest and lowest velocities.

and the anisotropy could be explained by horizontal shear movement of the upper mantle. If the upper mantle anisotropy is caused by the dynamical process of the upper mantle as was suggested by FUCHS (1977), absence of anisotropy may indicate that mantle convection in the upper mantle beneath the Canadian Shield does not exist. We may speculate that the existence of a pole of plate movement in the Canadian Shield may be supported by the nonexistence of anisotropy and high shear velocity in the upper mantle under this area.

We would like to thank Dr. Y. Ida for his critical reading of the manuscript and offering many useful suggestions. Discussion with Dr. S. Karato was helpful and exciting. Dr. K. Whitham, the former head of the Seismology division, Earth Physics branch, Energy Mines and Resources of Canada, provided one of us (M.H.) with beautiful seismic records while there as a Post Doctrate fellow. Our sincere thanks are due to him.

\section{REFERENCES}

ANDERSON, D. L. and B. R. JULIAN, Shear velocities and elastic parameters of the mantle, $J$. Geophys. Res., 74, 3381-3386, 1969. 
Anderson, D. L. and M. M. Toksöz, Surface waves on a spherical earth. 1, J. Geophys. Res., 68, 3483-3500, 1963.

BIswas, N. N., Earth-flattening procedure for propagation of Rayleigh wave, Pure Appl. Geophys., 96, 61-74, 1972.

Biswas, N. N. and L. KNOPOFF, Exact earth-flattening calculation for Love waves, Bull. Seismol. Soc. Am., 60, 1123-1137, 1970.

Brune, J. N., The Sa phase from Hindu Kush earthquake of July 6, 1962, Pure Appl. Geophys., 62, 81-95, 1965.

Brune, J. and J. N. Dorman, Seismic waves and earth structure in the Canadian Shield, Bull. Seismol. Soc. Am., 53, 167-210, 1963.

Buchbinder, G. G. R. and G. Poupinet, P-wave residual in Canada, Can. J. Earth Sci, 14, 12921304, 1977.

Calcagnile, G. and G. F. Panza, Vertical and SV components of Sa, Geophys. J. R. Astron. Soc., 38, 317-335, 1974.

CALor, P., Onde longitudinale e transversali guidate dall' astenofera, Rendi conti dell' academia nazional dei Lincei, Series VIII, XV, face 6, 15, 352-357, 1953.

Calor, P., L'astenosfera come canale-guida dell'energia sismica, Ann. Geofis., 7, 491-501, 1954.

CARA, M., Regional variations of higher Rayleigh-mode phase velocities: A spatial-filtering method, Geophys. J. R. Astron. Soc., 54, 439-460, 1978.

CARA, M., Lateral variation of $S$ velocity in the upper mantle from higher Rayleigh modes, Geophys. J. R. Astron. Soc., 57, 649-670, 1979.

CRAmpIN, S. and D. KING, Evidence for anisotropy in the upper mantle beneath Eurasia from the polarization of higher mode seismic waves, Geophys. J. R. Astron. Soc., 49, 59-85, 1977.

DunkIn, J. W., Computation of modal solution in layered elastic media at high frequencies, Bull. Seismol. Soc. Am., 55, 335-358, 1965.

DzIewonski, A. M. and D. L. ANDERson, Preliminary reference earth model, Phys. Earth Planet. Inter., 25, 297-356, 1981.

ForsYTH, D. W., The early structural evolution and anisotropy of the oceanic upper mantle, Geophys. J. R. Astron. Soc., 43, 103-162, 1975.

Fuchs, K., Seismic anisotropy of the subcrustal lithosphere as evidence for dynamical processes in the upper mantle, Geophys. J. R. Astron. Soc., 49, 167-179, 1977.

Gold, B. and C. M. RAder, Digital Processing of Signals, McGraw-Hill, New York, 1969.

HASHIzUME, M., Two earthquakes on Baffin Island and tectonic implications, J. Geophys. Res., 78, 6069-6081, 1973.

HaSHzUme, M., Surface wave study of earthquake near northwestern Hudson Bay, Canada, J. Geophys. Res., 79, 5458-5468, 1974.

Hashizume, M., Surface-wave study of the Canadian Shield, Phys. Earth Planet. Inter., 11, 333$351,1976$.

Hashizume, M., Surface-wave study of Labrador Sea earthquake 1971 December, Geophys. J. $R$. Astron. Soc., 51, 149-168, 1977.

Haskell, N. A., The dispersion of surface waves of multilayered media, Bull. Seismol. Soc. Am., 43, 17-34, 1953.

Helmberger, D. V. and G. R. Engen, Upper mantle shear structure, J. Geophys. Res., 79, 4017$4028,1974$.

IBRAHIM, A. H. and O. W. NuTTLI, Travel-time curves and upper mantle structure from long period S waves, Bull. Seismol. Soc. Am., 57, 1063-1092, 1967.

JoRDan, T. H., The continental tectosphere, Rev. Geophys. Space Phys., 13, 1-12, 1975a.

JoRDAN, T. H., Lateral heterogeneity and mantle dynamics, Nature, 257, 745-750, $1975 \mathrm{~b}$.

KaUsel, E. G., F. SchWAB, and E. MAntovani, Oceanic Sa, Geophys. J. R. Astron. Soc., 50, 407$440,1977$. 
KaWASaki, I., The near-field Love waves by the exact ray method, J. Phys. Earth, 26, 211-237, 1978.

KIRKWOOD, S.C. and S. CRAMPIN, Surface-wave propagation in an ocean basin with an anisotropic upper mantle: Numerical modelling, Geophys. $J$. R. Astron. Soc., 64, 463-485, 1981a.

KIRKWood, S. C. and S. CRAmpIN, Surface-wave propagation in an ocean basin with an anisotropic upper mantle: Observations of polarization anomalies, Geophys. J. R. Astron. Soc., 64, 487-497, 1981b.

Kovach, R. L. and D. L. ANDERson, Higher mode surface waves and their bearing on the structure of the earth mantle, Geophys. J. R. Astron. Soc., 54, 161-182, 1964.

Kovach, R. L. and E. A. Robinson, Upper mantle structure in the Basin and Range Province, western North America, from the apparent velocities of S waves, Bull. Seismol. Soc. Am., 59, 1653-1665, 1969.

MCEviLLY, T. V., Central U.S. crust-upper mantle structure from Love and Rayleigh wave phase velocity inversion, Bull. Seismol. Soc. Am., 54, 1997-2015, 1964.

Mitchell, B. J. and R. HerRmann, Shear velocity structure in the eastern United States from the inversion of surface wave group and phase velocities, Bull. Seismol. Soc. Am., 69, 1133$1148,1979$.

NAKANISH, K., F. SchWAB, and E. G. KAUSEL, Interpretation of $S a$ on a continental structure, Geophys. J. R. Astron. Soc., 47, 211-223, 1976.

Poupinet, G., Heterogeneites dumanteau terrestre deduites de la propagation des ondes ve volume implication geodynamique, These presentee a l'Universite Scientifique et Medical de Grenoble, 1977.

Poupinet, G., On the relation between P-wave travel time residuals and the age of continental plates, Earth Planet. Sci. Lett., 43, 149-161, 1979.

Priestly, K., J. A. ORCUTt, and J. BRUNe, Higher-mode surface waves and the structure of Great Basin of Nevada and western Utah, J. Geophys. Res., 85, 7166-7174, 1980.

Romanowicz, B. A., Seismic structure of the upper mantle beneath the United States by three dimensional inversion of body wave arrival times, Geophys. J.R. Astron. Soc., 57, 479-506, 1979.

SArTo, M., Excitation of free oscillation and surface waves by a point source in vertically heterogeneous earth, J. Geophys. Res., 72, 3689-3699, 1967.

Wickens, A. J. and G. G. R. BuCHBinder, S-wave residuals in Canada, Bull. Seismol. Soc. Am., 70, 807-822, 1980. 